\title{
Prólogo a la vigésimonona edición alemana
}

Por ser muchas las modificaciones y ampliaciones que me han sido propuestas por los numerosos adeptos de este libro, no pudieron ser teridas en cuenta todas en esta nueva edición. La razón principal de esto fué el coste elevado de los trabajos tipográficos, circunstancia que nos obligó a ser parcos en la reforma de la actual edición.

La taila de "antilogaritmos" de cuatro cifras ha vuelto a ser adoptada, a petición de muchos de nuestros lectores. Como tablas nuevas figuran dos auxiliares correspondientes a las principales VIr y XII.

La tabla auxiliar de la VII está destinada para calcular los análisis elementales de compuestos orgánicos ricos en nitrógeno. En estos casos supone un error el tomar la temperatura en números redon teados - según es lo corriente - , sin tener en cuenta las correspondientes correcciones de presion. Dichos errores resultan eliminados tomando en consideración la mencionada tabla auxiliar. Para más detalles sobre este particular, véase el estudio de $E$. Mohr que se cita en la página 1.4.

La tabla auxiliar de la XrI presta buenos servicios al aforar vasijas volumétrucas, como matraces, pipetas, etc., indicadoras de volúmenes redondeados (so: 1 las vas jas corrientes del comercio). Dicha tabla permite calcular de manera fácil la diferencia entre el volumen de la vasija y el que debe tener a la temperatura normal; basta para ello pesar la vasija llena de agua a cualquier temperatura.

Dicha tabla auxiliar da inmediatamente el peso del agua contenida en una vasija exacta a la temperatura normal, cuando la pesada se hace a tempera'ura distinta. Teniendo este dato 
real de la pesada se llega fácilmente a determinar el error de una vasija a la temper atura normal. Fn esta tabla se han omitido los logaritmos de los pesos del litro, porque se trata esencialmente de números redondearios que se pueden multiplicar sin necesidad de logaritmos por los pesos del litro.

En esta edición die las tablas logaritmicas se han tomado en cuenta correcciones y mejoras enviadas por los señores siguientes: cand. ing. MI. Apfelbaum, Viena; Dr. G. Bruhns, Charlottenburgo; quínico ell jefe L. Chaveau, Casablanca (Marrueros); Iaboratorios Fresenius, Wiesbaden; estudiante Otto Hecht, Charlottenburgo; Dr. W. Herrmann, J.everkusen; Dr. W. von Heygendortf, Leipzig; Dr. H. Kreusler, Charlottenburg; prof. Dr. E. Molnr, Heidelberg; Dr. M. C. Nenburger, Viena; prof. Dr. W. A. Roth, Brunsiga; químico en jefe Dr. R. Saar, Halle a. d. Saale. A todos los auttedichos señores doy mis más sinceras gracias y solicito de ellos su colaboración futura en anśioga forma.

Agradeceria que todas las observaciones fueran dirigidas a mi domicilio, Weissenbung Strasse, 36, Miaburg (Lahn).

A. THIEL 